\title{
Structural Analysis and Test Comparison of a 20-Meter Inflation-Deployed Solar Sail
}

\author{
David W. Sleight \\ NASA Langley Research Center, Hampton, VA 23681 \\ Troy Mann ${ }^{\dagger}$ \\ Swales Aerospace, Hampton, VA 23681 \\ David Lichodziejewski ${ }^{\ddagger}$, and Billy Derbès \\ L'Garde, Inc., Tustin, CA 92780
}

\begin{abstract}
Under the direction of the NASA In-Space Propulsion Technology Office, the team of L'Garde, NASA Jet Propulsion Laboratory, Ball Aerospace, and NASA Langley Research Center has been developing a scalable solar sail configuration to address NASA's future space propulsion needs. Prior to a flight experiment of a full-scale solar sail, a comprehensive test program was implemented to advance the technology readiness level of the solar sail design. These tests consisted of solar sail component, subsystem, and sub-scale system ground tests that simulated the aspects of the space environment such as vacuum and thermal conditions. In July 2005, a 20-m four-quadrant solar sail system test article was tested in the NASA Glenn Research Center's Space Power Facility to measure its static and dynamic structural responses. Key to the maturation of solar sail technology is the development of validated finite element analysis (FEA) models that can be used for design and analysis of solar sails. A major objective of the program was to utilize the test data to validate the FEA models simulating the solar sail ground tests. The FEA software, ABAQUS, was used to perform the structural analyses to simulate the ground tests performed on the $20-\mathrm{m}$ solar sail test article. This paper presents the details of the FEA modeling, the structural analyses simulating the ground tests, and a comparison of the pretest and post-test analysis predictions with the ground test results for the $20-\mathrm{m}$ solar sail system test article. The structural responses that are compared in the paper include loaddeflection curves and natural frequencies for the beam structural assembly and static shape, natural frequencies, and mode shapes for the solar sail membrane. The analysis predictions were in reasonable agreement with the test data. Factors that precluded better correlation of the analyses and the tests were unmeasured initial conditions in the test set-up.
\end{abstract}

\section{Introduction}

$S^{\text {so }}$ olar sails are examples of ultra-low mass and deployable space structures called gossamer structures. Solar sails have been proposed for a variety of future space exploration missions and provide a cost effective source of propellantless propulsion. Solar sails span very large areas to capture and reflect photons from the Sun and are propelled through space by the transfer of momentum from the photons to the solar sail. ${ }^{1,2,3,4}$ The thrust of a solar sail, though small, is continuous and acts for the life of the mission without the need for propellant. Recent advances in materials and ultra-low mass gossamer structures have enabled a host of useful space exploration missions utilizing solar sail propulsion. The team of L'Garde, NASA Jet Propulsion Laboratory (JPL), Ball Aerospace, and NASA Langley Research Center, under the direction of the NASA In-Space Propulsion Office (ISP), has been developing a scalable solar sail configuration to address NASA's future space propulsion needs. The 100-m baseline solar sail concept shown in Fig. 1 was optimized around the one astronomical unit (AU) Geostorm mission, ${ }^{5,6}$ and

\footnotetext{
* Aerospace Engineer, Computational Structures and Methods Branch/Research \& Technology Directorate, MS 155, AIAA Member.

${ }^{\dagger}$ Aerospace Engineer, Swales Aerospace, Structural Dynamics Branch/Research \& Technology Directorate, MS 230, AIAA Member.

\# Aerospace Engineers, Manager/Engineer, AIAA Members.
} 
features a $2 \mu$-thick metalized Mylar sail membrane with a net/membrane sail suspension architecture with inflationdeployed sail support beams consisting of inflatable sub- $\mathrm{T}_{\mathrm{g}}$ (glass transition temperature) rigidizable semimonocoque booms and a spreader system shown in Fig. $2 .^{7,8,9}$. The solar sail has vanes integrated onto the tips of the support beams to provide full 3 -axis control of the solar sail. ${ }^{10,11}$ This same structural concept can be scaled to meet and exceed the requirements of a number of other NASA missions.

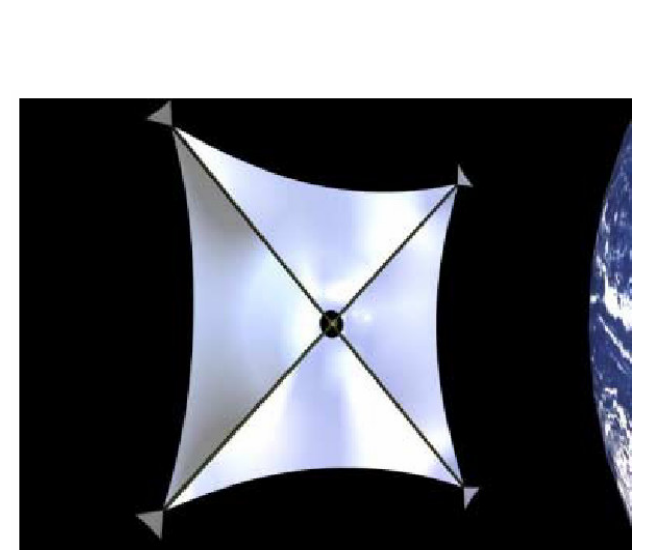

Figure 1. L'Garde 100-m ISP solar sail design

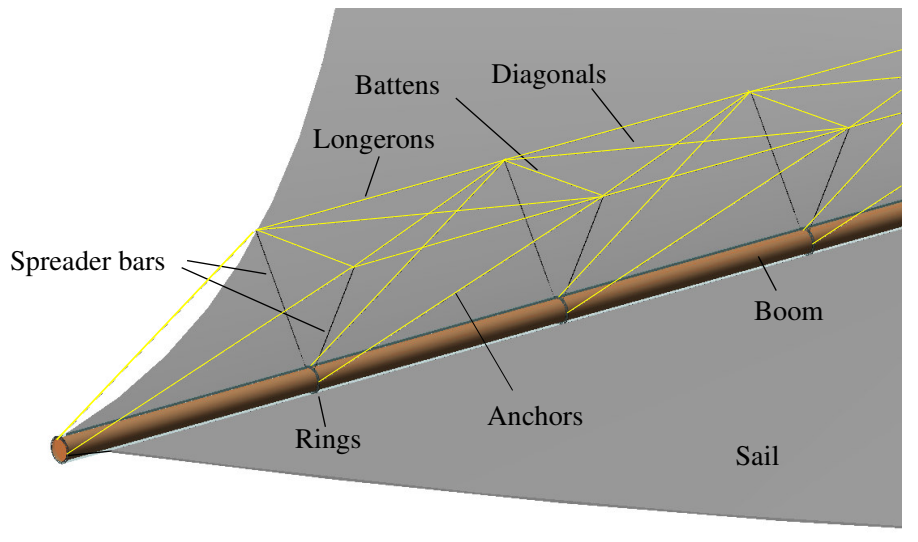

Figure 2. Spreader system of beam assembly

Prior to a flight experiment of a full-scale solar sail, a comprehensive 3-phase test program was implemented to advance the technology readiness level of the solar sail design., $7,12,13,14,15$ In phase 1 of the program, a test plan was created consisting of solar sail component, sub-system, and sub-scale system ground tests that simulated the vacuum and thermal environments of space with the limitation of being tested within Earth's gravitational field. In phase 2 of the program, boom component test articles of the solar sail were initially tested to determine material and section properties. Next, a 7.4-m rigidized beam assembly subsystem test article, which represents one of the four sail support beams of a $10-\mathrm{m}$ sub-scale solar sail test article, was tested under static and dynamic loading conditions at the NASA Goddard Space Flight Center (GSFC) Thermal Vacuum Chamber in December 2003. The highlight of phase 2 of the program was the successful testing of a 10-m four-quadrant sub-scale solar sail system test article in vacuum and thermal environment conditions at the 30-m Space Power Facility (SPF) vacuum chamber, located at the NASA Glenn Research Center (GRC) Plum Brook Station in Sandusky, Ohio in July 2004. Testing of the 10 -m solar sail test article included vacuum deployment, and structural statics and vibration tests of one of the beam assemblies and one quadrant of the sail membrane. In phase 3 of the program, a $20-\mathrm{m}$ four-quadrant solar sail system test article was tested in the SPF to measure its static and dynamic structural responses in June-July 2005. The four-quadrant sub-scale solar sail test article shown in Fig. 3 represents the central 20 meters of the $100-\mathrm{m}$ solar sail configuration. Testing of the $20-\mathrm{m}$ solar sail test article included a vacuum deployment test and structural statics and vibration tests of two of the beam assemblies and the entire four-quadrant sail

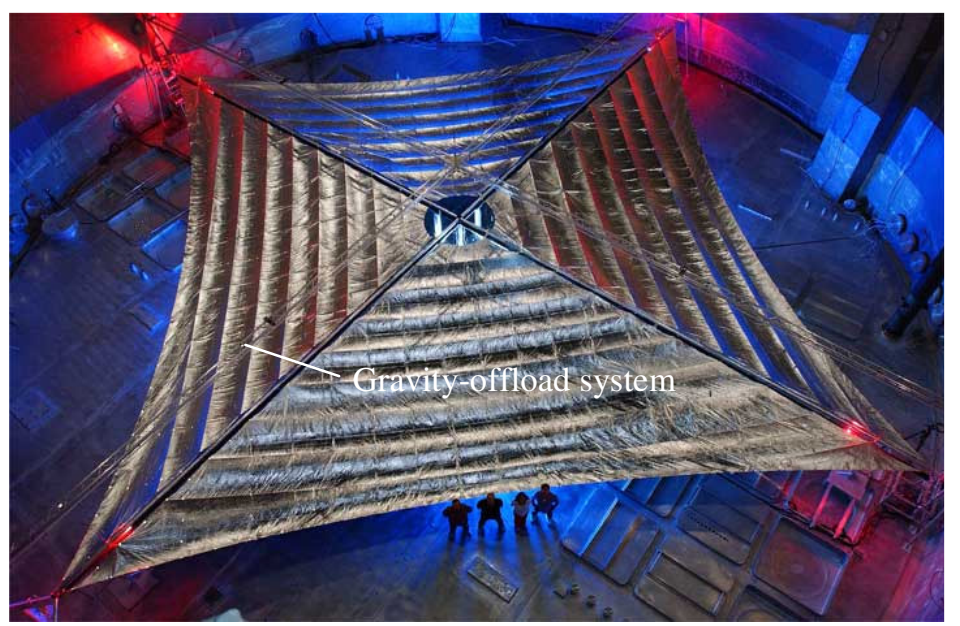

Figure 3. 20-m solar sail system tested at the NASA GRC Plum Brook Station Space Power Facility

membrane. To mitigate the effect of gravity, an overhead suspension system was used to offload the solar sail ground tests.

Due to the large size of solar sails envisioned for future space missions, testing of full-scale test articles is not possible in existing test facilities. Therefore, validated finite element analysis (FEA) models and methods for solar sails are needed for design and analysis of future solar sail missions. An important aspect of the 3-phase program 
was to develop FEA models to simulate the solar sail ground tests and validate the results with the ground test data. In phase 2 of the program, two FEA software packages, NEiNastran ${ }^{16}$ and ABAQUS ${ }^{17}$, were used to model and simulate the 7.4-m beam assembly sub-system ground test and the 10-m four-quadrant solar sail sub-scale system ground test. ${ }^{18,19}$ The models were developed based on the cumulative test and analysis correlation results of previous component and sub-scale tests. The FEA predictions were in reasonable agreement with the ground test data. In phase 3 of the program, ABAQUS was used to perform the pre-test and post-test FEA structural response predictions for the 20-m solar sail system ground sail test. The objectives of this paper are to present the FEA structural response predictions for the $20-\mathrm{m}$ four-quadrant solar sail sub-system ground test and compare with the experimental data from the ground test in phase 3 of the program. Details of the 20-m four-quadrant solar sail subscale system ground test and finite element (FE) analyses are described in the following section.

\section{20-Meter Solar Sail Ground Test and Structural Analysis}

A 20-m four-quadrant solar sail system sub-scale test article was tested in the SPF in vacuum conditions at the NASA GRC Plum Brook Station in June-July 2005 in two test configurations. ${ }^{14,15}$ The first test configuration was a sail membrane configuration with four sail/net membrane quadrants attached to the rings on the booms. The sail membrane configuration was used to measure the static sail membrane shape using photogrammetry and vibration frequencies and mode shapes using laser vibrometry under a combined simulated solar flux loading and gravity loading condition. The targets used in the photogrammetry measurements can be seen in Fig. 5 as the illuminated dots on the sail membrane. The second test configuration was the beam structural assembly with the four sail/net membrane quadrants replaced with lightweight Kevlar strings located between the last four ring stations on the beams of the test article. The strings were chosen such that their weight in a 1-g gravity field would represent the solar pressure imparted on the sail during operation. Three static load-deflection tests and a structural dynamics test were performed in vacuum conditions on the beam assembly test configuration. The static load-deflection tests measured the beam assembly static deflections subjected to a vertical bending load case, a horizontal bending load case, and a torsional load case. A test assembly with actuators and load cells was constructed on the ends of the North and South booms in the SPF to apply the test loads and measure the deflections and rotations in the booms. The structural dynamics test measured the natural frequencies and mode shapes with accelerometers placed along the length of the booms. In both test configurations, cold plates were placed directly below the booms on both test configurations to simulate the space environment where the booms would rigidize by the sub- $\mathrm{T}_{\mathrm{g}}$ cold rigidization process. $^{8}$

In Phase 3 of the program, NASA LaRC developed computational models and performed geometrically nonlinear analyses of the 20-m solar sail system ground demonstrator test article using the ABAQUS FEA software package. The models were based on the cumulative test results and previous sub-scale models developed in the Phase 2 effort of the ISP Solar Sail Program. An important function of the structural analyses was to provide pre-test predictions of the expected structural response that were needed to help plan the tests. After the tests, correlation efforts were performed to refine the models to reduce the difference between the analysis results and the measured test data. The following sections describe the finite element modeling, structural analysis details, and the comparison of the ground test and structural analysis results for the $20-\mathrm{m}$ solar sail system ground demonstrator test.

\section{A. 20-m Sail Membrane Static Shape/Structural Dynamics Test and Analysis}

\section{20-m Sail Membrane Static Shape/Structural Dynamics FEA Model}

The 20-m four-quadrant solar sail system test article was fixed at the central hub of the solar sail. The position coordinates for the sail membrane shape were measured by photogrammetry with 768 reflective targets placed on the sail membrane. The reflective targets used in the photogrammetry can be seen in Fig. 4 as the illuminated dots on the sail membrane. A high-density line of targets was put at the quadrant centerlines to obtain better data for the shape of the sail billow. For the sail membrane structural dynamics test, the excitation was provided by two electromagnetic shakers placed on the North and South beam tips, where one magnet excited the structure laterally, and the other one excited the structure vertically. The natural frequencies and mode shapes of the sail membrane were measured by laser vibrometry.

The ABAQUS v6.5-4 FEA software package was used in the analyses of the 20-m sail membrane static shape and structural dynamics test for the 20-m sail system. Fig. 5 shows the post-test FE model of the sail membrane test configuration of the 20-m solar sail system test article. The post-test ABAQUS sail membrane model consisted of 45,321 elements and 25,172 nodes. The post-test FE model was refined after the test to include the photogrammetry reflective targets and actual masses of the $20-\mathrm{m}$ sail membrane test configuration measured during the test set-up. The FE model included the gravity-offload system to correctly represent as accurately as possible the actual test 
configuration of the 20-m sail system. The model utilized membrane elements for the sail membrane; beam elements for the booms, spreader bars, and balance bars of the gravity-offload system; and truss elements for the Kevlar tensioned lines in the beam assemblies. The model included concentrated mass elements to account for added masses such as accelerometers, wires, photogrammetry targets, and other masses measured during the test set-up. The other masses measured during the test for the sail membrane and beam assembly components were adjusted by modifying the density of the materials used in the components. The boundary conditions of the 20-m sail system were fixed in all six degrees of freedom (DOF) at the hub of the sail and pinned in the translation degrees of freedom at the top of the gravity-offload system. In addition, the fulcrum of each balance bar of the gravity-offload system was fixed in all DOF's except for rotation in the planes parallel to booms.

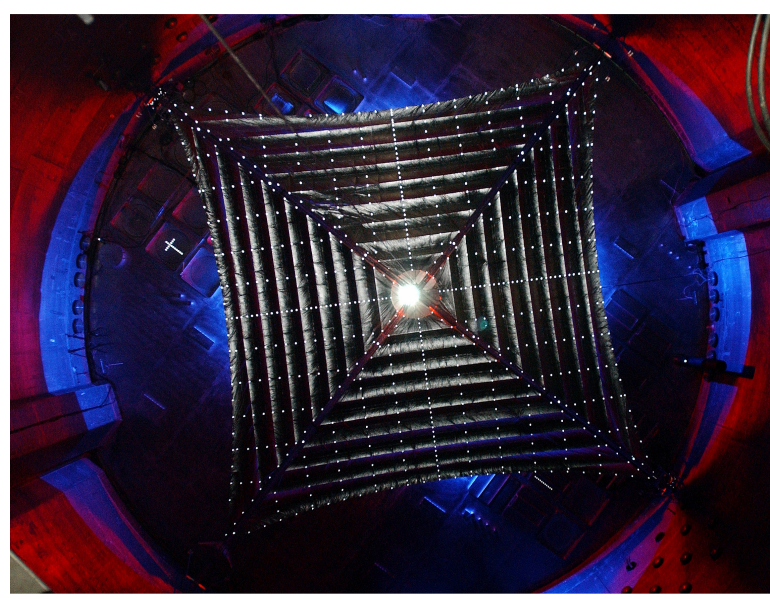

Figure 4. 20-m solar sail system with photogrammetry reflective targets

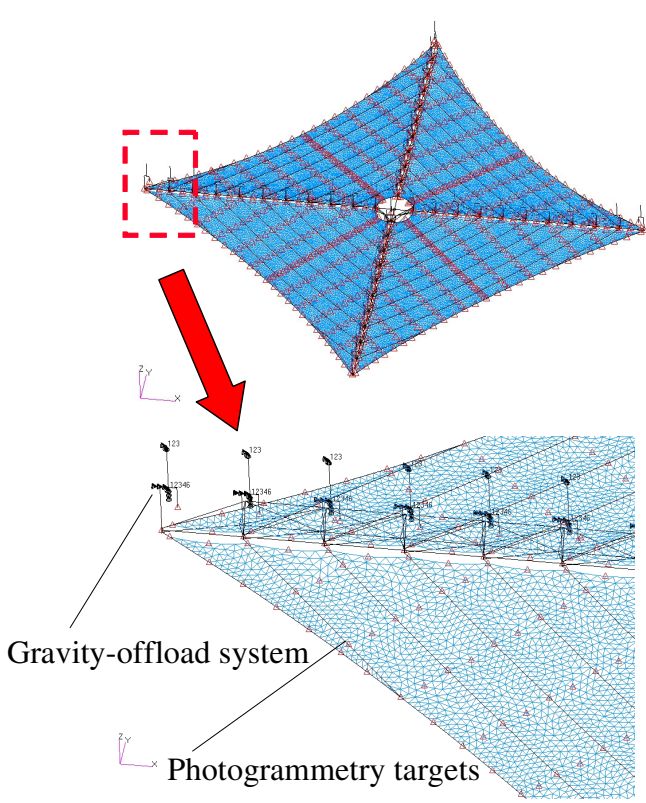

Figure 5. 20-m solar sail system tested at the NASA GRC Plum Brook Station Space Power Facility

\section{20-m Sail Membrane Static Shape/Structural Dynamics Test and Analysis Results}

A geometrically nonlinear analysis with a sequence of multiple loading steps was performed using ABAQUS on the $20-\mathrm{m}$ sail membrane test configuration. First, a pre-tensioning load was applied to the battens in the spreader bar system of the beams. Next, a gravity load was applied to the model. Lastly, the vibration frequencies and mode shapes about the nonlinear stressed state were determined for the sail membrane structural dynamics solution. The ABAQUS stabilization feature was employed to achieve convergence in the highly nonlinear analysis. Fig. 6 shows a contour plot of the out-of-plane deformation of the $20-\mathrm{m}$ sail membrane due to the gravity loading for the post-test analysis results. The analysis showed a maximum boom tip deflection of $-0.0061 \mathrm{~m}$ and a maximum sail deflection of $-0.0576 \mathrm{~m}$. A comparison of the static out-of-plane shape for the ABAQUS analysis results and the photogrammetry shape data is shown in Fig. 7. The static out-of-plane shape for the analysis was determined by

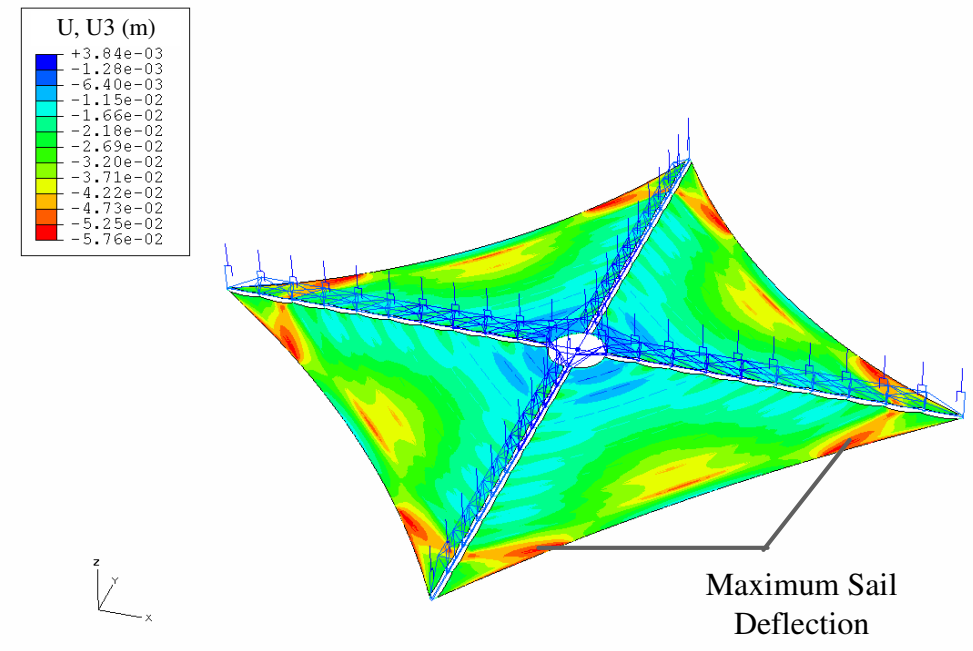

Figure 6. 20-m sail system FEA out-of-plane deflection due to gravity loading

4

American Institute of Aeronautics and Astronautics 
adding the out-of-plane sail membrane deformations, $\mathrm{W}$, to the coordinates of original undeformed geometry, $\mathrm{Z}_{0}$, of the finite element model. The photogrammetry data measured the coordinates of the sail position. The contour plots show that maximum billow of the sail occurs at the center of each sail quadrant near the outer edges. The regions along the booms shown in blue are an artifact of plotting the data and should be ignored since only the sail membrane shape is being plotted in both Figs. 7 a) and b). The ABAQUS analysis showed good qualitative agreement with the measured photogrammetry shape of the sail membrane, but under-predicted the sail billow by about $25 \%$ compared to the photogrammetry test data. The difference between the photogrammetry test data and the ABAQUS analysis shown in Fig. 8 revealed that the $20-\mathrm{m}$ sail membrane test configuration was slightly tilted and produced a greater difference in the out-of-plane static shape on the North-East quadrant of the sail membrane. This may be attributed to the uncertainties of the test set-up's initial conditions and boundary conditions resulting from the gravity-offload system. Also, the difference in the out-of-plane shape comparison may be attributed to wrinkling of the sail membrane, which reduces the effective modulus of the Mylar sail material and was not accounted for in the analyses.

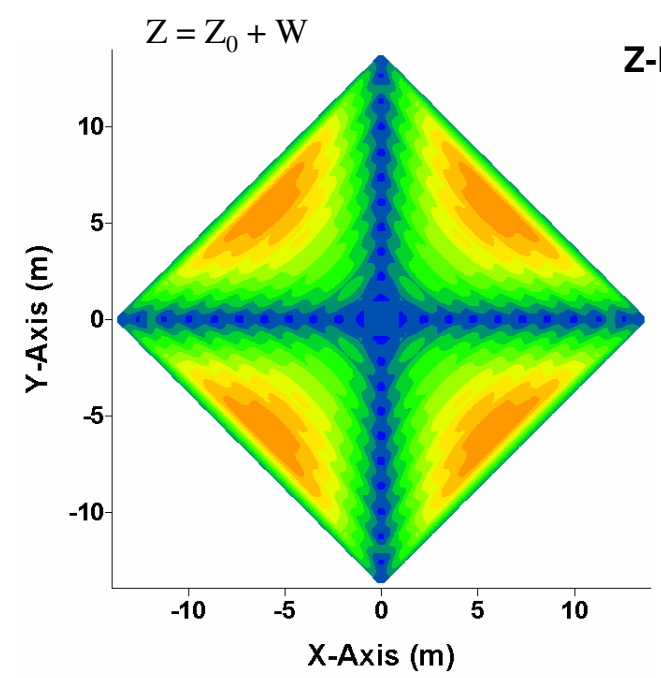

(a) ABAQUS FEA Results
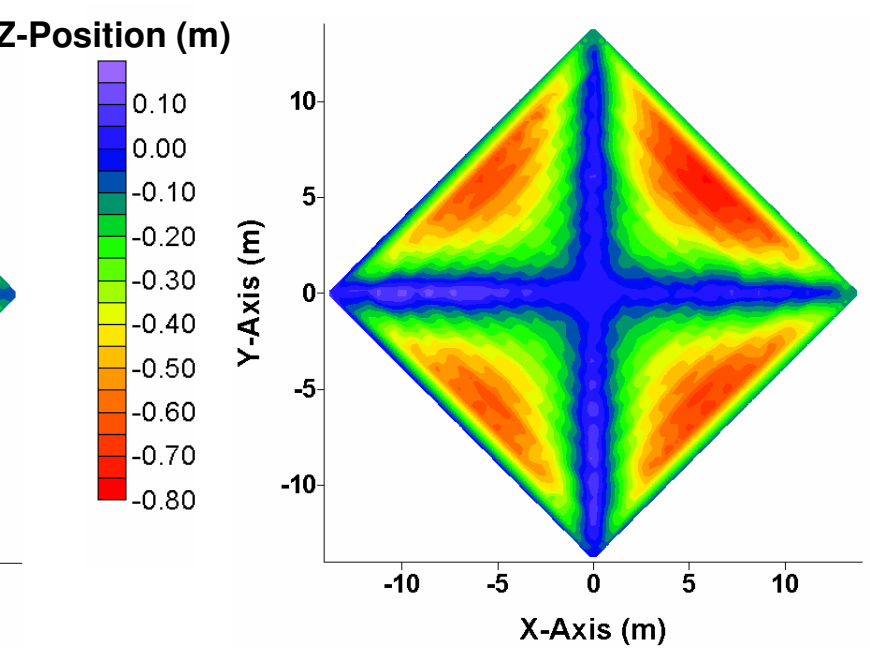

(b) Photogrammetry Test Data

Figure 7. 20-m sail membrane out-of-plane static shape test and FEA results

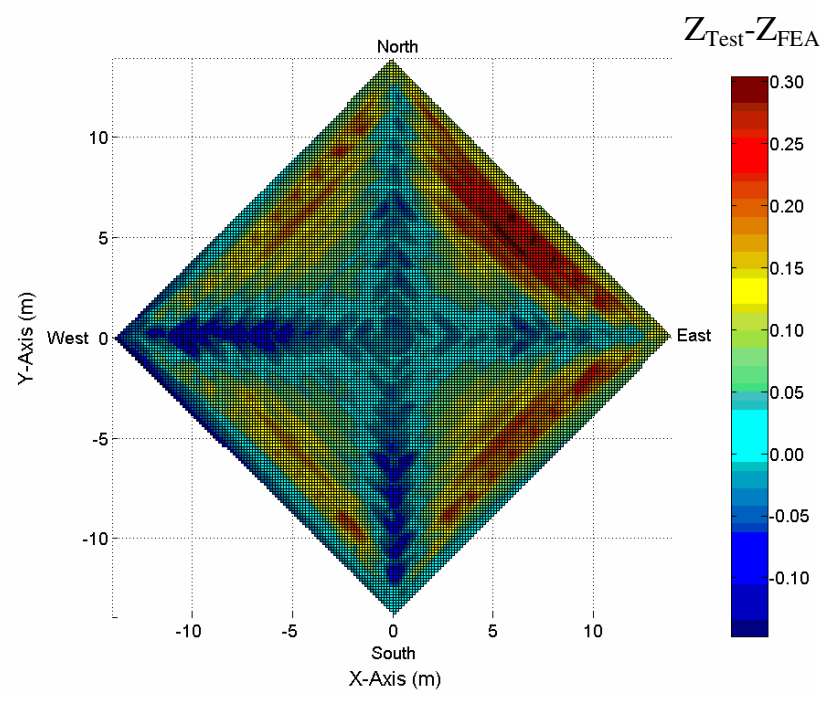

Figure 8. 20-m sail membrane test and FEA out-of-plane static shape difference. 
A comparison of three frequencies measured during the test and the FEA pre-test and post-test analysis predictions are presented in Table 1 for the $20-\mathrm{m}$ sail membrane structural dynamics test in a vacuum environment. The frequencies denoted with asterisks are the measured frequencies from only the southeast (SE) sail quadrant from the laser vibrometry test data whereas the other listed test frequencies are the measured frequencies of the fourquadrant sail system. The numbers in parentheses are the percent error differences between the measured test frequencies and the ABAQUS predicted analysis frequencies. The post-test analysis was modified to include the masses of the 20-m sail system measured during the test set-up. Qualitative comparisons of the test and FEA mode shapes are shown in Figs. 9-11. The first mode shape in Fig. 9 is a drum mode shape where each sail membrane quadrant is vibrating up and down in the out-of-plane direction. The second mode shape in Fig. 10 is a mode shape where each sail membrane quadrant is oscillating up and down in two half sine waves along the outer edge. The third mode shape in Fig. 11 is a mode shape where each sail membrane quadrant is flapping up and down in an alternating sequence between the outer edge and the center sail membrane regions. The ABAQUS predictions for the pre-test and post-test FEA analyses showed excellent agreement with the measured test frequency for the first mode shape. Both the pre-test and post-test FEA predictions were within 5\% of the measured test frequency for the first mode shape. The FEA predictions over-predicted the measured test frequencies by $18 \%$ and $23 \%$ for modes 2 and 3, respectively; for the pre-test analysis results and by $-10 \%$ and $-14 \%$ for modes 2 and 3, respectively, for the post-test analysis results. A quantitative comparison of the mode shapes for the SE sail quadrant is presented in Table 1 using the Modal Assurance Criterion (MAC). The MAC was used to establish a measure of how close the mode shapes from the ABAQUS analysis were to the measured test mode shapes. MAC values range from 0 (no correlation between shapes) to 1 (full correlation). Values above 0.9 are generally considered as very-well correlated. Values below 0.6 may or may not indicate correlation. The MAC values show that all modes predicted by the FEA are in good agreement with the test mode shapes. However, a test mode shape at a frequency of $1.05 \mathrm{~Hz}$ was measured in the test, but a corresponding mode shape was not predicted in the analysis with a MAC value greater than 0.6. This test frequency was omitted in the test and analysis comparison. The difference between the test and analysis results may be attributed to not accounting for wrinkling in the analyses which reduces the effective modulus of the Mylar sail material.

Table 1. Comparison of 20-m sail membrane structural dynamics test and FEA frequencies with MAC values

\begin{tabular}{|c|c|c|c|c|}
\hline Mode & $\begin{array}{c}\text { Test Frequency } \\
(\mathrm{Hz})\end{array}$ & $\begin{array}{c}\text { Pre-Test Analysis } \\
\text { Frequency }(\mathrm{Hz})\end{array}$ & $\begin{array}{c}\text { Post-Test Analysis } \\
\text { Frequency }(\mathrm{Hz})\end{array}$ & MAC Value (Post-Test) \\
\hline 1 & $0.829 * / 0.841$ & $0.87(+3.4 \%)$ & $0.83(-1.3 \%)$ & 0.7409 \\
\hline 2 & 1.31 & $1.55(+18.3 \%)$ & $1.56(+19.1 \%)$ & 0.8267 \\
\hline 3 & $1.45^{*} / 1.44$ & $1.30(-9.7 \%)$ & $1.24(-13.9 \%)$ & 0.8081 \\
\hline
\end{tabular}

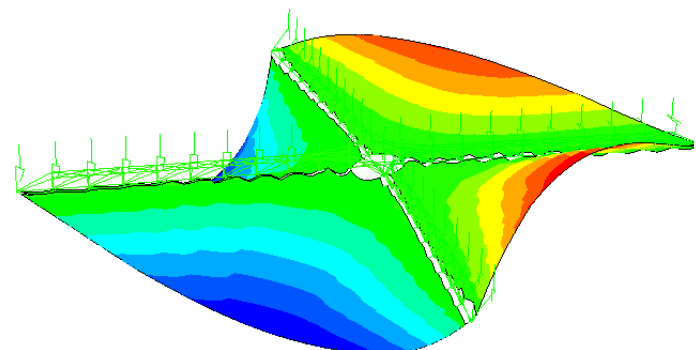

a) ABAQUS FEA Results

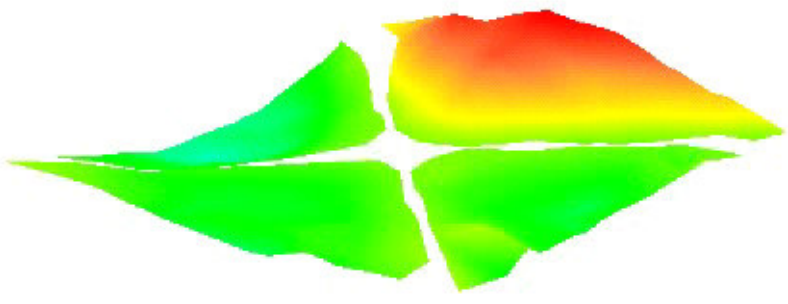

b) Test Results

Figure 9. Mode shape \#1 comparison for 20-m sail membrane structural dynamics test and FEA results 


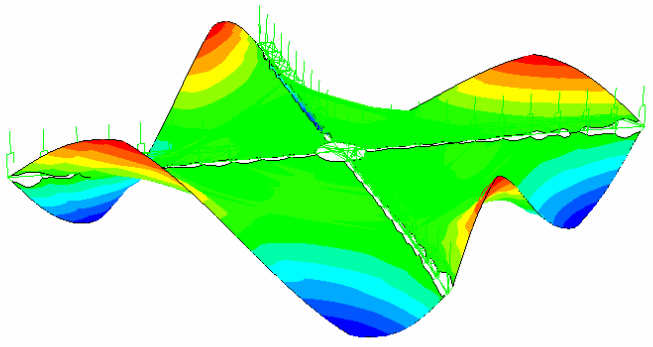

a) ABAQUS FEA Results

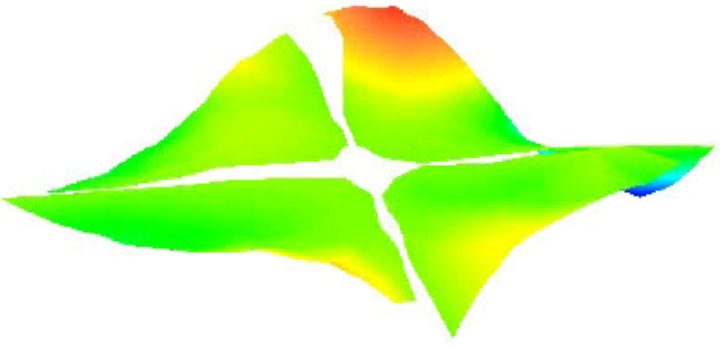

b) Test Results

Figure 10. Mode shape \#2 comparison for 20-m sail membrane structural dynamics test and FEA results

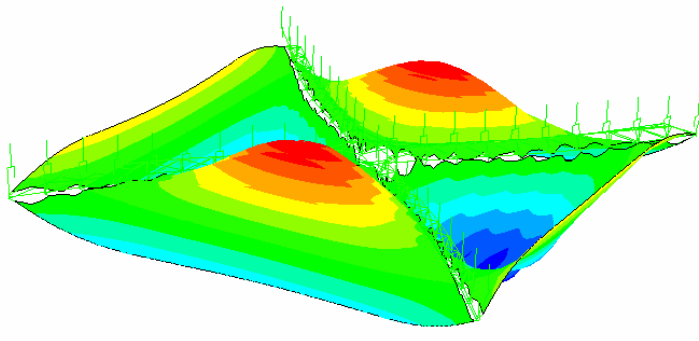

a) ABAQUS FEA Results

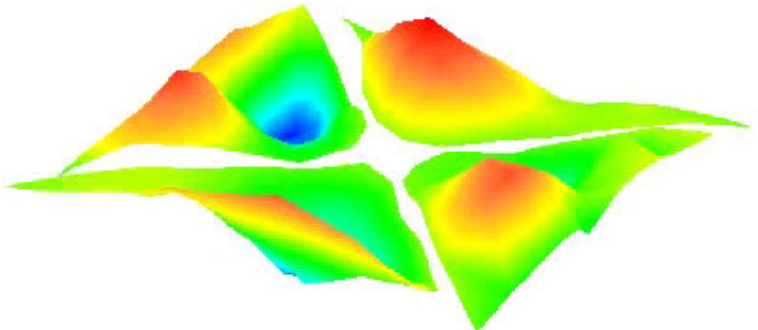

b) Test Results

Figure 11. Mode shape \#3 comparison for 20-m sail membrane structural dynamics test and FEA results

\section{B. 20-m Beam Structural Assembly Statics/Dynamics Test and Analysis}

\section{20-m Beam Structural Assembly Statics/Dynamics FEA Model}

In the second test configuration of the 20-m solar sail system test article, the four sail membrane quadrants were removed and replaced with lightweight Kevlar strings to simulate a solar flux loading condition in the space environment. The $20-\mathrm{m}$ four-quadrant solar sail system test article was again fixed at the central hub of the solar sail. A structural dynamics test and three static load-deflection tests were performed in vacuum conditions. A test assembly was constructed with actuators and load cells on the ends of the North and South booms to apply the test loads and measure the deflections and rotations in the booms. The structural dynamics test measured the natural frequencies and mode shapes with accelerometers placed along the length of the booms.

The ABAQUS v6.5-4 FEA software package was used in all the analyses for the 20-m beam assembly structural statics and dynamics test. The post-test ABAQUS FEA model of the 20-m beam assembly test article with the gravity-offload system is shown in Fig. 12 and includes 4,125 elements and 9,220 nodes. The post-test model was updated to include the actual masses of the beam assembly measured during the test set-up. The model utilized beam elements for the booms, spreader bars, and balance bars of the gravity-offload system; and truss elements for the Kevlar tensioned lines in the beam assemblies. The model included concentrated mass elements to account for added masses such as accelerometers, wires, and other masses measured during the test set-up. The boundary conditions of the 20-m beam assembly test article were fixed in all six degrees of freedom (DOF) at the hub of the beam assembly system and pinned in the translation degrees of freedom at the top of the gravity-offload system. In addition, the fulcrum of each balance bar of the gravity-offload system was fixed in all DOF's except for rotation in the planes parallel to booms. 


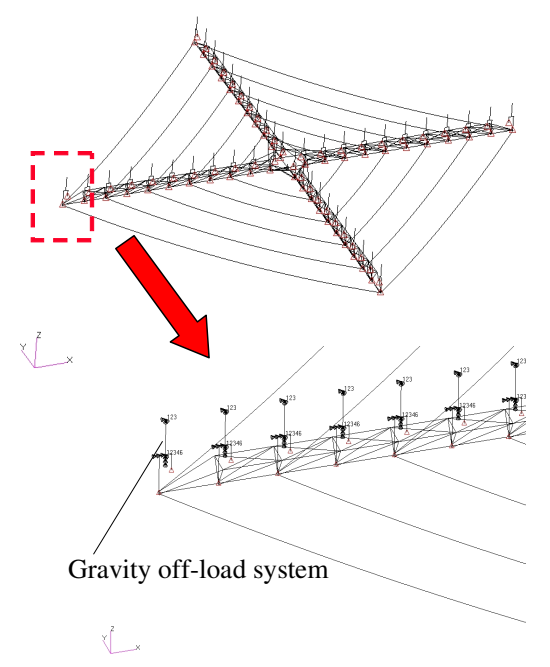

\section{Figure 12. ABAQUS FEA model of the 20-m beam structural assembly test configuration}

\section{20-m Beam Structural Assembly Statics/Dynamics Test and Analysis Results}

For the 20-m beam assembly structural static analysis, a geometrically nonlinear analysis with a sequence of multiple loading steps was performed using ABAQUS to predict the structural statics behavior of the 20-m beam structural assembly. The FEA model was identical to the model used in the $20-\mathrm{m}$ beam assembly structural dynamics analysis with the exception of a different loading sequence. The loading steps were applied in the following sequence. First, a pre-tensioning load was applied to the battens in the spreader bar system of the beams. Next, a gravity load was applied to the model. Lastly, the test loading conditions (out-of-plane bending, lateral bending, and torsion) as shown in Fig. 13 were applied on the North and South boom tips. The loads were applied as symmetric loads at the same time on the North and South booms. The ABAQUS stabilization feature was again employed to achieve convergence in the highly nonlinear analysis of the 20 -m beam assembly test configuration.

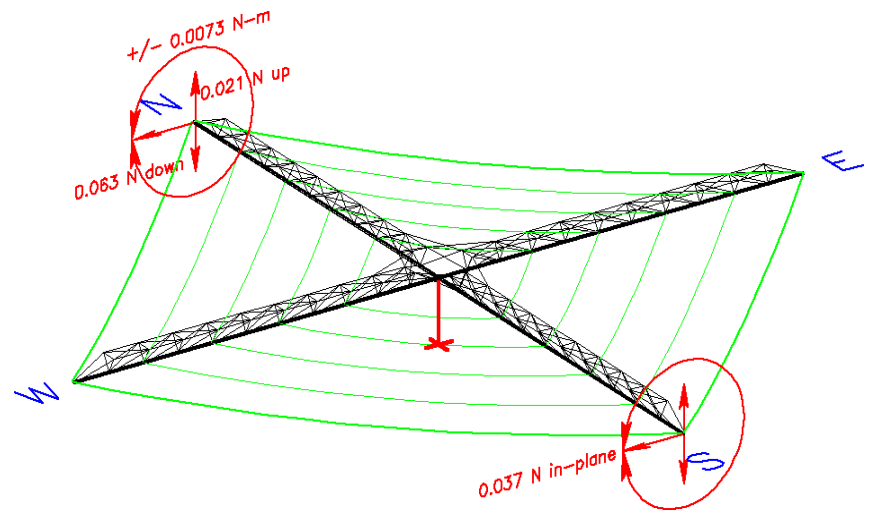

Figure 13. Loading and boundary conditions for the 20-m beam structural assembly static tests

In performing the initial comparison of the test results with the post-test FEA predictions, the results indicated that the test structure exhibited a much stiffer behavior than the FEA model predictions for the out-of-plane bending tests. After some investigation of the test set-up, it was concluded that the gravity-offload system itself could be causing first order uncertainties in the measured test results due to where the strings on the gravity-offload system were attached to the balance bars. According to Greschik ${ }^{20}$, the fulcrum location offset of the balance bars can introduce geometric stiffness to system and must be carefully considered in testing and modeling. Figure 13 shows the details of the gravity-offload system. In the gravity-offload test set-up, Kevlar strings which offloaded the booms were run through small holes drilled through a $5-\mathrm{mm}$ diameter composite bar and tied with a knot at the opposite 
end. Since the gravity-offload system was not calibrated and the initial tilt angle of the balance bars was not recorded in the tests, the location of the pivot point of the Kevlar lines was unknown and could vary for each of the 44 balance bars of the gravity-offload system. The location of the pivot point of the strings attached to the balance bars could create an undesired restoring force as the balance bar was tipped in response to the applied loading. These restoring forces could become prohibitively large on the same order of magnitude as the applied test loads and affect the amount of boom deflection. As a result of this investigation, the FE model was updated to consider the details of the gravity-offload system. Originally, the modeling assumption was made that the Kevlar strings attached to the balance bar had no offset of the fulcrum location - that is they were attached to the balance bar along its mid-plane through the thickness. The FEA model was updated to offset the nodes at the location where the Kevlar strings were attached to the balance bar. The nodal offset locations in all balance bars were assumed to be the locations where the string knot was tied through the small holes in the balance bar (denoted by red circles) as shown in Fig. 14 a). An alternative modeling scheme shown in Fig. 14 b) where the nodes were offset to the location where the Kevlar strings made contact with the balance bar was also used for the modeling of all the balance bars. However, the alternate modeling scheme of the balance bars predicted FEA results that were in greater error with the beam assembly static tests results. Other modeling schemes could also be considered that are dependent on the tilt angle of the balance bars. Again, since the initial tilt angle of the balance bars was not recorded during the tests, it is difficult to know the true test set-up conditions necessary for modeling and simulating accurately the test. Clearly, it is very important to understand the impact of all boundary conditions on the structural behavior of the 20-m beam assembly since the analysis predictions and presumably the test results are very sensitive to the details of the gravity-offload system. The structural static FEA results presented below are based on the modeling scheme 1 presented in Fig. 14 a).

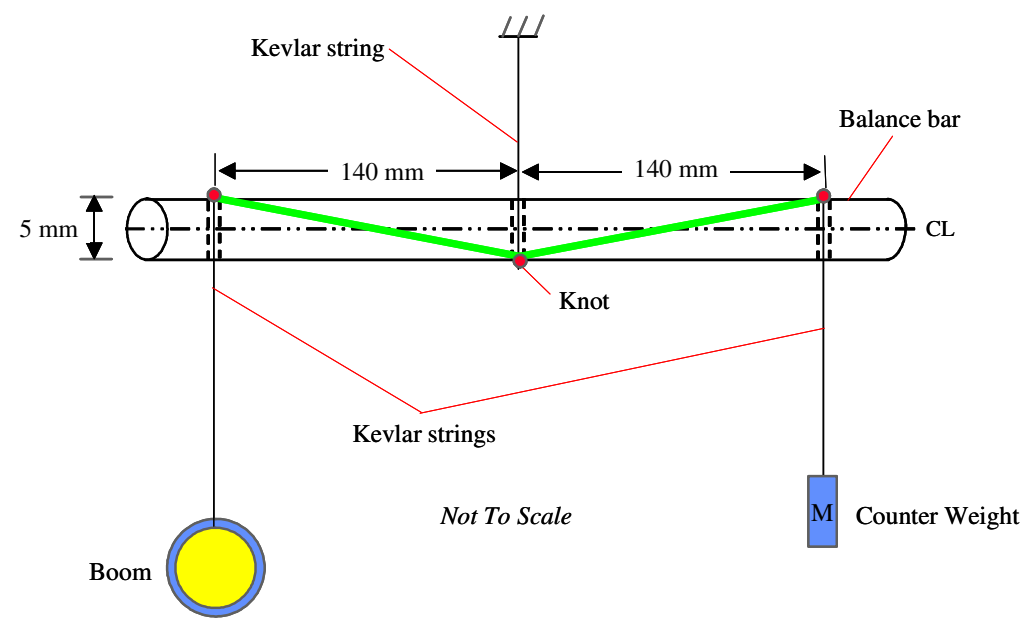

a) Modeling scheme 1 of gravity-offload system

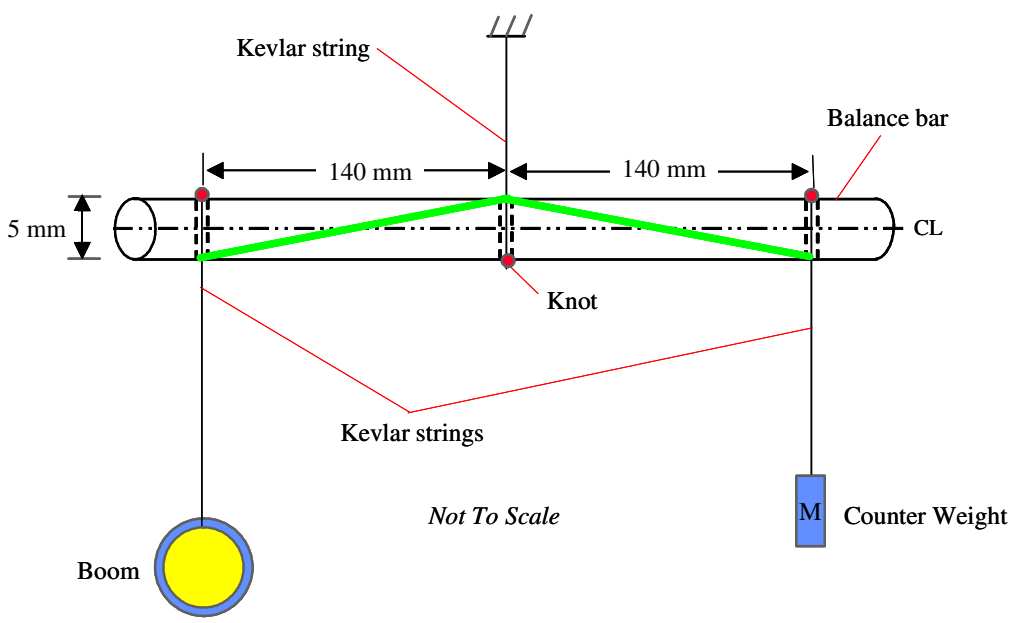

b) Modeling scheme 2 of gravity-offload system

Figure 14. FEA modeling of the balance bar of the gravity-offload system

American Institute of Aeronautics and Astronautics 
Two separate out-of-plane bending tests were conducted on the 20-m beam assembly to apply out-of-plane bending loads in downward and upward loading directions with linear actuators on the North and South booms as shown in Fig. 13. The loads were applied as symmetric loads at the same time on the North and South booms. In the test, the out-of-plane bending loads were initially applied in the desired upward or downward loading direction and then reversed to return the boom to its original position. The FEA pre-test analyses did not include the modeling of the gravity-offload system because the analysis was having convergence difficulties at the time when pre-test predictions were presented at a test readiness review to help plan the test. The model was instead analyzed in a manner similar to the 10 -m beam assembly analysis in phase 2 of the program. ${ }^{18}$ That is, point forces equivalent to the measured masses of the gravity-offload system were applied at the ring locations to level the beam assembly after a gravity load was applied to the model. Since the individual masses of the booms of the beam assembly were not known before the test, the same mass was used in all four booms in the pre-test analysis predictions. Therefore, the North and South booms had the same deflections. Later, the analysis was successfully performed to achieve converged solutions with the gravity-offload system. The post-test model was modified to include the masses of the 20-m beam assembly system measured during the test set-up.

The load-deflection curve for the downward out-of-plane bending test is presented in Fig. 15 for the test results and the FEA pre-test and post-test predictions. The test results show a significant difference in the boom tip deflections for the North and South booms with the North boom being much stiffer than the South boom. Also, note

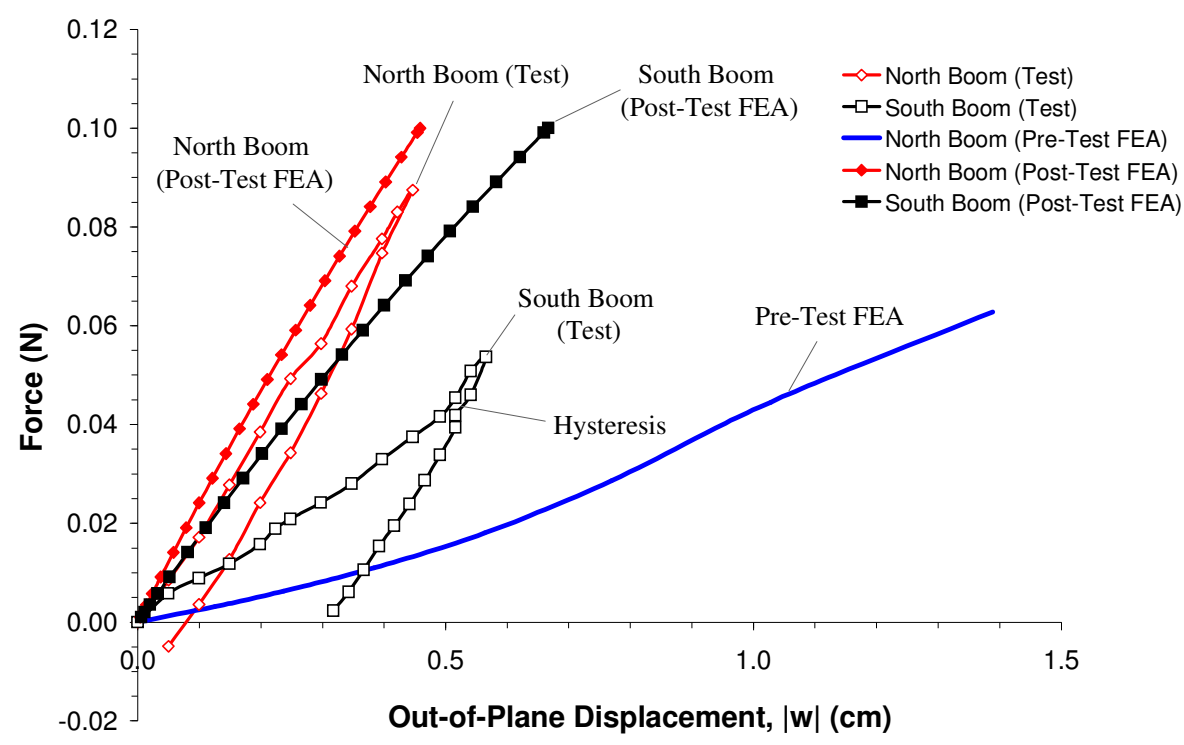

Figure 15. 20-m beam structural assembly downward out-of-plane bending test and FEA results

that the amount of load applied to the North boom was nearly double the load applied to the South boom even though they were supposed to be the same during the test. The post-test FEA predictions showed good correlation with the test results for the North boom, but poor correlation with the test results for the South boom. The test data for the South boom showed an unexplained hysteresis effect where the initial downward loading test results exhibited a much softer behavior than the test results for the reversed loading of the boom. During the manufacturing process, each boom was manufactured separately and could possess different material properties. However, material tests were not conducted on any of the booms. In the analysis, the same material properties were used in all four booms and were obtained from boom component tests conducted earlier in the program. In pre-test analysis studies, the FEA predictions showed that the model was sensitive to the forces applied to the ring locations to level the beam assembly. This was due to the uncertainty in the final mass of the beam assembly and how its mass was distributed along the structure. The pre-test results predicted much more deflection than the measured test results due to the uncertainties of the pre-test mass estimates of the gravity-offload system. The load-deflection curve for the upward out-of-plane bending test is presented in Fig. 16 for the test results and the FEA pre-test and post-test results. The out-of-plane bending load was initially applied upward and then reversed to its original position in the test. The post-test FEA results showed good correlation with the test results for the South boom and poor correlation for the North boom. However, the test data for the North boom showed a significant hysteresis 
effect in the upward and reversed loading directions. The pre-test analysis predictions over-predicted the deflection of the upward bending test due to the uncertainty in the mass of the beam assembly before the test.

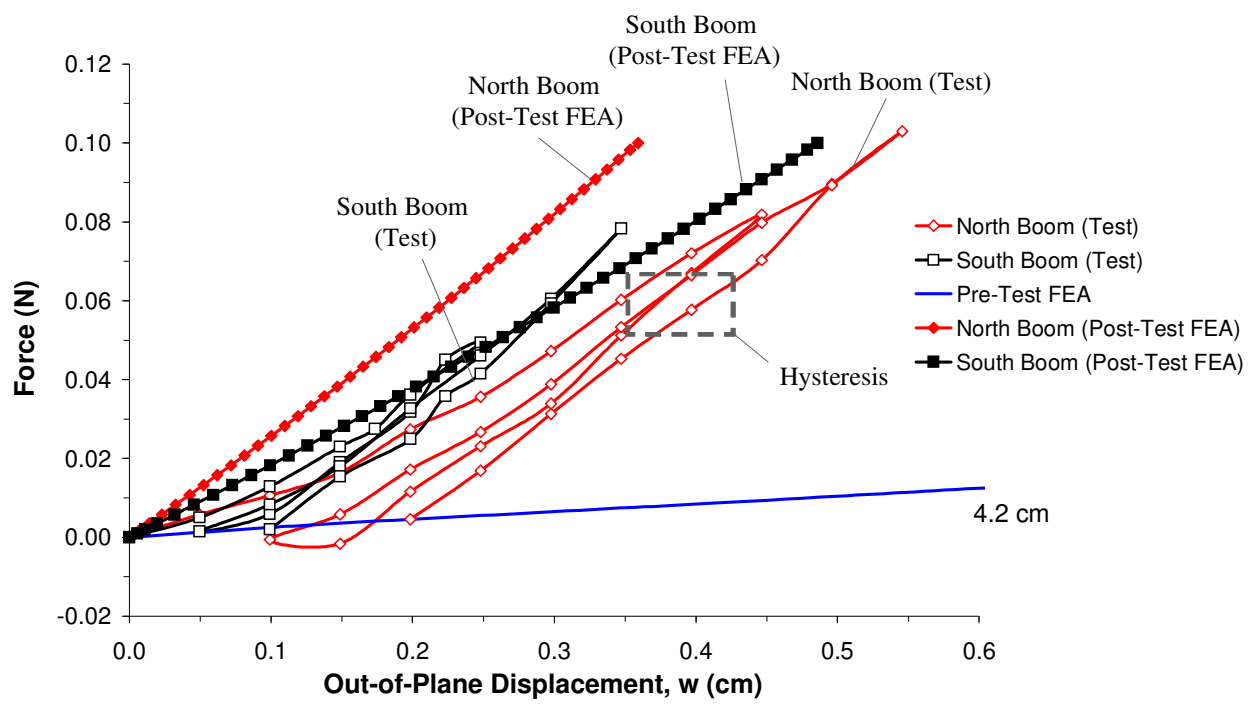

Figure 16. 20-m beam structural assembly vertical out-of-plane bending test and FEA results

A lateral bending test was conducted on the 20-m beam assembly to apply symmetric lateral bending loads using linear actuators on the North and South booms as shown in Fig. 13. The load-deflection curve for the lateral bending test is presented in Fig. 17 for the test results and the FEA pre-test and post-test results. In the test, the lateral bending loads were applied initially in one direction on both the North and South booms and then reversed to the booms original position. Test data was available for only the North boom. The test results showed that the 20-m beam assembly was significantly more flexible in the lateral loading direction than the pre-test and post-test FEA results. This behavior was most likely the result that only the booms contributed to the stiffness of the 20-m beam assembly system without any contribution from the spreader bar system during the test. An analysis of a model with only the booms was performed which was much closer to the test data. One uncertainty in the 20-m beam assembly analysis was the stiffness of the Kevlar lines at very low load levels since no test data was available. Another

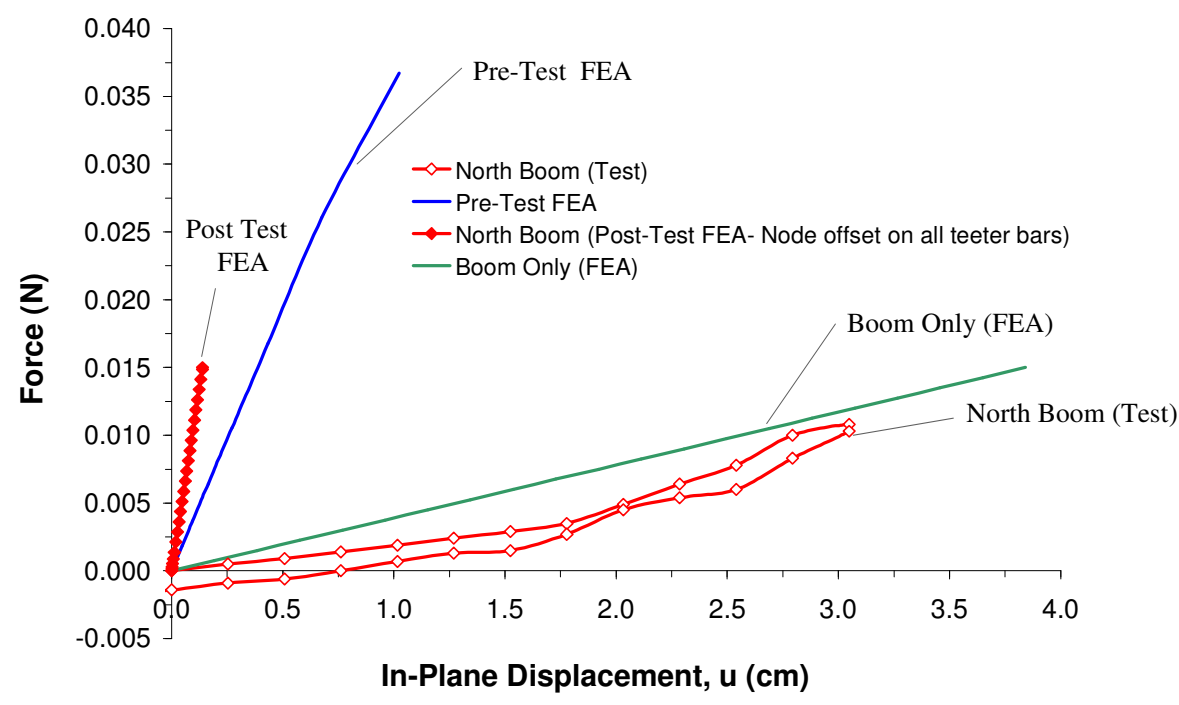

Figure 17. 20-m beam structural assembly lateral bending test and FEA results 
contributing factor in the analysis of the 20-m beam assembly was the lack of data for the initial tension or slack in the Kevlar lines of the spreader bar system. In the analysis, there was assumed to be no initial slack or tension. However, if the Kevlar lines in the spreader bars system had slack in the lines during the test, then the overall stiffness of the 20-m beam assembly system would be reduced causing more deflection of the beams. This theory is consistent with the measured test results. In the future, more analyses should be performed to investigate the effect of slackness in the Kevlar lines which may improve the FEA results with the lateral bending test data.

A torsion loading test was conducted on the 20 -m beam assembly to apply torsion loads in clockwise (CW) and counter clockwise (CCW) directions using linear actuators on the North and South booms as shown in Fig 13. The load-deflection curves are presented in Figs. 18 and 19 for the test results and the FEA post-test results for the North and South booms, respectively. The pre-test predictions closely matched the post-test results and are not shown in the figures. The test results showed that the $20-\mathrm{m}$ beam assembly experienced a nonlinear behavior at low load levels of the test as shown in the load-deflection curves. The North boom test results showed nearly symmetric rotations in both loading directions as shown in Fig. 18. However, the South boom showed much more boom rotation in the clockwise direction than the counter clockwise direction. The pre-test and post-test FEA results predicted less beam twist compared to the test data as shown in the figures. The nonlinear behavior experienced in the test was most likely the result of initial slackness in the Kevlar lines or nonlinearity in the material properties of the Kevlar lines at low load levels that was not accounted for in the analyses. However, the slope of the loaddeflection curves at higher load levels in the test is closer to the slope of the load-deflection curve predicted by the analyses. In the future, more analyses should be performed to investigate the effect of slackness in the Kevlar lines which may improve the FEA results with the torsional loading test data.

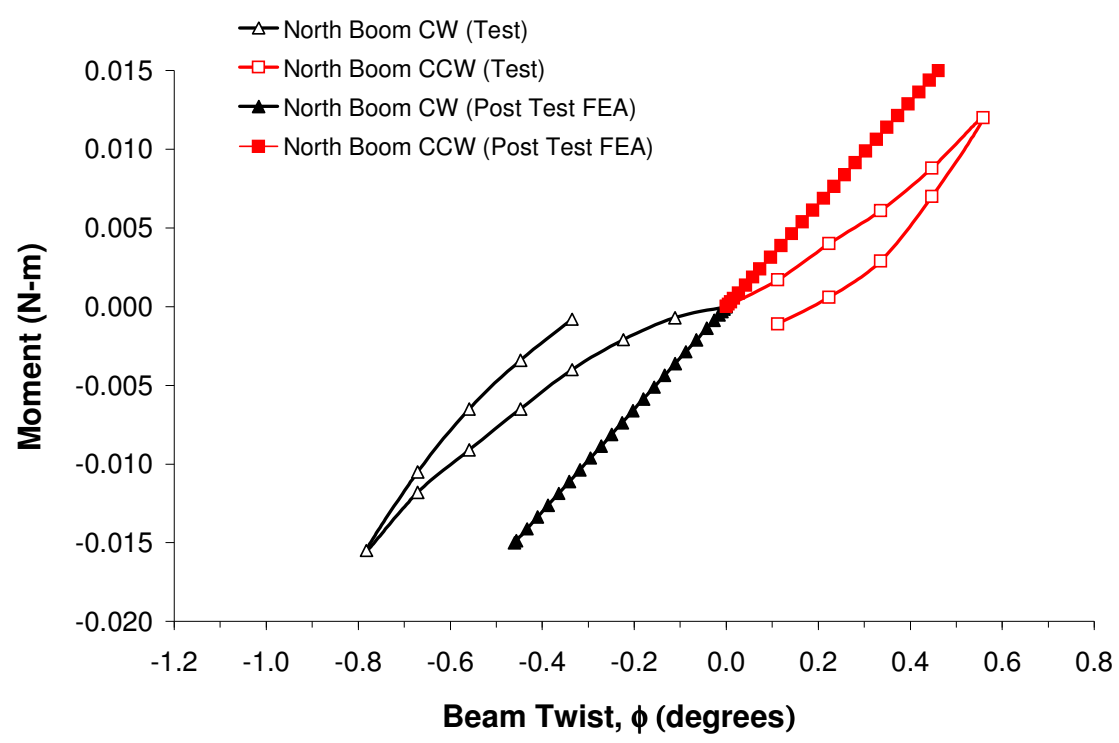

Figure 18. 20-m beam structural assembly torsion test and FEA results for the North beam 


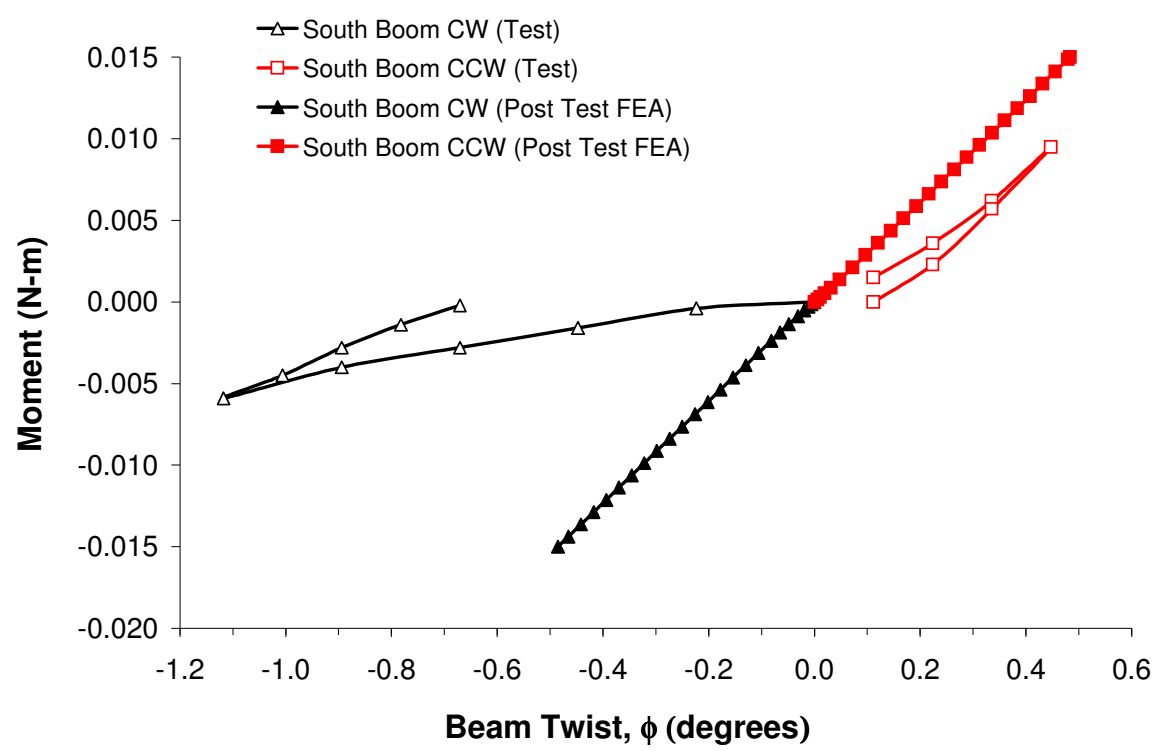

Figure 19. 20-m beam structural assembly torsion test and FEA results for the South beam

A geometrically nonlinear analysis with a sequence of multiple loading steps was performed using ABAQUS to predict the structural dynamics behavior of the $20-\mathrm{m}$ beam assembly test configuration. The FEA model was identical to the model used in the 20-m beam assembly structural statics analysis with the exception of a different loading sequence. First, a pre-tensioning load was applied to the battens in the spreader bar system of the beam assembly. Next, a gravity load was applied to the model. Lastly, the vibration frequencies and mode shapes about the nonlinear stressed state were determined for the beam assembly structural dynamics solution. The ABAQUS stabilization feature was again employed to achieve convergence in the highly nonlinear analysis of the $20-\mathrm{m}$ beam assembly test configuration.

A comparison of the first three frequencies measured during the test and the corresponding FEA pre-test and post-test analysis predictions are presented in Table 2 for the $20-\mathrm{m}$ beam assembly structural dynamics test. The numbers in parentheses are the percent error differences between the measured test frequencies and the ABAQUS analysis frequencies. The ABAQUS analysis for the pre-test FEA results showed reasonable agreement with the measured test frequencies for the first four mode shapes. The ABAQUS post-test analysis was modified to include the actual masses of the 20-m sail system measured during the test set-up. The post-test FEA results using the updated model were in good agreement with the measured test frequencies. Comparisons of the 20-m beam assembly mode shapes are shown in Figs. 20-22. The test results show clear peaks in the measured frequency response functions that correlate well with modes identified in the finite element analysis results. However, the lack of spatial resolution in the test sensors to measure the mode shapes of the $20-\mathrm{m}$ beam assembly makes quantitative comparison with the FEA predictions very difficult, if not impossible. Nevertheless, the beam structural dynamics tests were greatly improved compared with the 10-m beam assembly test results performed in phase 2 of the program, but additional accelerometers would have greatly improved measurements and comparison with the FEA predictions.

Table 2. Comparison of 20-m beam structural assembly dynamics test and FEA frequencies

\begin{tabular}{|c|c|c|c|}
\hline Mode & $\begin{array}{c}\text { Test Frequency } \\
(\mathrm{Hz})\end{array}$ & $\begin{array}{c}\text { Pre-Test Analysis } \\
\text { Frequency }(\mathrm{Hz})\end{array}$ & $\begin{array}{c}\text { Post-Test Analysis } \\
\text { Frequency }(\mathrm{Hz})\end{array}$ \\
\hline 1 & 0.594 & $0.45(-24.2 \%)$ & $0.54(-9.1 \%)$ \\
\hline 2 & 0.641 & $0.51(-20.4 \%)$ & $0.59(-8.0 \%)$ \\
\hline 3 & 1.31 & $1.46(+11.5 \%)$ & $1.36(+3.8 \%)$ \\
\hline
\end{tabular}




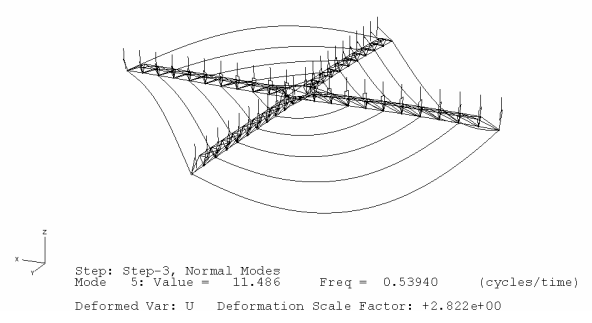

a) ABAQUS FEA Results

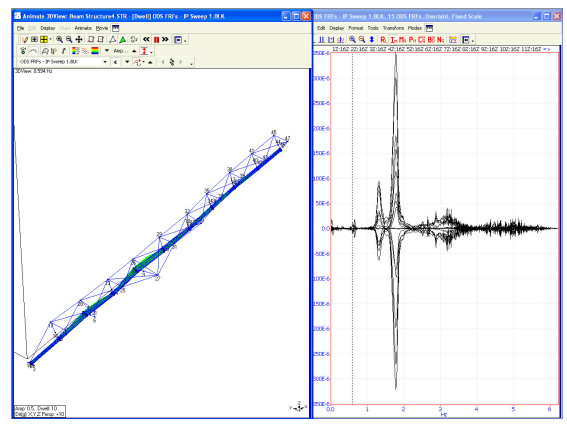

b) Test Results

Figure 20. First mode shape comparison for 20-m beam structural assembly dynamics test and FEA results

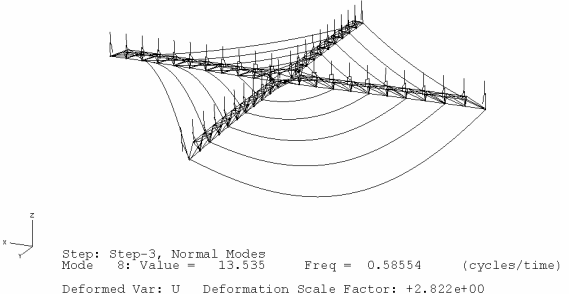

a) ABAQUS FEA Results

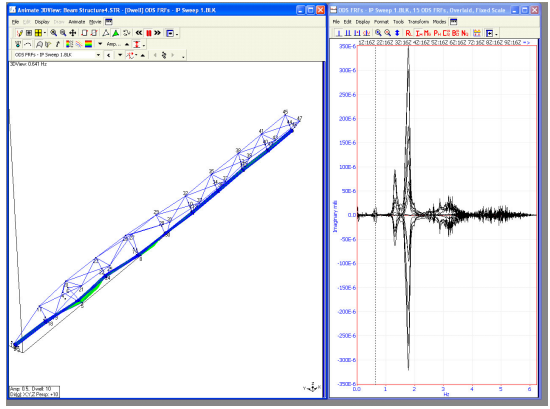

b) Test Results

Figure 21. Second mode shape comparison for $20-\mathrm{m}$ beam structural assembly dynamics test and FEA results

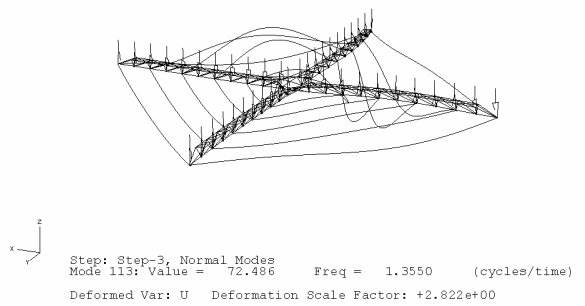

a) ABAQUS FEA Results

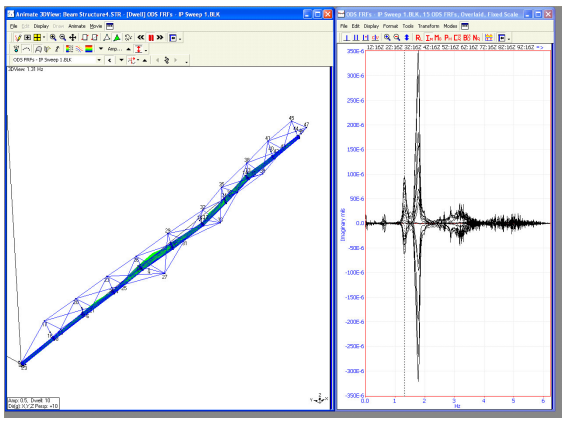

b) Test Results

Figure 22. Third mode shape comparison for 20 -m beam structural assembly dynamics test and FEA results

\section{Summary}

The team of L'Garde, NASA JPL, Ball Aerospace, and NASA LaRC has developed a highly scaleable solar sail configuration to meet and exceed the requirements of many of NASA's future missions. Since testing of full-scale solar sail test articles is not possible due to size limits of existing test facilities, validated finite element analysis (FEA) models and methods for solar sails are needed for design and analysis of future solar sail missions. A comprehensive phased test and analysis plan was implemented to permit validation of both the solar sail test articles and the FEA models. In phase 3 of the program, a 20-m four-quadrant solar sail system test article was tested in the 
30-m Space Power Facility vacuum chamber at the NASA GRC Plum Station. This paper presented the structural analyses using the finite element analysis software package, ABAQUS, to simulate the ground testing of a $20-\mathrm{m}$ solar sail test article and the comparison of the analysis predictions with the test results. Comparisons were made of pre-test and post-test analysis predictions with the test data including load-deflection curves from static load tests and vibration frequencies and mode shapes from vibration tests. The pre-test and post-test predictions simulating the 20-m sail membrane static shape and structural dynamics test showed good correlation with the test data. The 20-m sail membrane static shape and structural dynamic FEA predictions differed from the test results by less than $25 \%$. Future analyses are recommended to be performed with updated material properties for the Mylar sail membrane including wrinkling prediction methodologies to improve correlation with the test data. The pre-test and post-test predictions simulating the $20-\mathrm{m}$ beam assembly structural dynamics test also showed good correlation with the test data. The beam assembly structural dynamic FEA post-test predictions differed from the test results by less than $10 \%$ for the first three measured frequencies. However, the lack of spatial resolution in the test sensors to measure the mode shapes made a quantitative comparison based on the mode shapes of the test and analysis results very difficult. The pre-test and post-test predictions simulating the $20-\mathrm{m}$ beam assembly structural statics were in reasonable agreement for some of the test results and in poor agreement for other test results. A factor that precluded better correlation of the analyses and the test results was the possibility that the gravity-offload system was causing undesired additional forces to be applied during the tests on the same order of magnitude as the applied test loads. Since the gravity-offload system was not calibrated and the initial tilt angle of the balance bars was not recorded in the test, it is difficult to know the true test set-up conditions necessary for accurately modeling and simulating the test. In addition, the initial slack in the Kevlar tension lines, which greatly influences the measured test results, was unknown during the test. For future work it is recommended that the specific details of the gravity-offload test set-up be accurately recorded and understood, and that additional analyses and studies be performed to investigate the structural statics behavior of the 20 -m beam assembly.

\section{Acknowledgments}

The work described in this paper was funded in whole or in part by the In-Space Propulsion Technology Program, which is managed by NASA's Science Mission Directorate in Washington, D.C., and implemented by the In-Space Propulsion Technology Office at Marshall Space Flight Center in Huntsville, Alabama. The program objective is to develop in-space propulsion technologies that can enable or benefit near- and mid-term NASA space science missions by significantly reducing cost, mass or travel times.

The authors also gratefully acknowledge the contributions of Dr. John Chen of the Computational Structures and Materials Branch (CSMB) at NASA Langley Research Center, Hampton, VA for his technical assistance in performing the structural analyses.

\section{References}

\footnotetext{
${ }^{1}$ Wright, J., Space Sailing, Taylor and Francis Publishers, 1992.

${ }^{2}$ McInnes, C. R., Solar Sailing: Technology, Dynamics, and Mission Applications, Springer-Praxis Series in Space Science and Technology, 1999.

${ }^{3}$ Chmielewski, A. B., “Advanced Concepts," Gossamer Spacecraft: Membrane and Inflatable Structures Technology for Space Applications, Edited by C.H.M. Jenkins, Progress in Astronautics and Aeronautics, Vol. 191, American Institute of Aeronautics and Astronautics, Reston, VA, 2001.

${ }^{4}$ Salama, M., McInnes, C. R., and Mulligan, P., "Gossamer Spacecraft Technology," Gossamer Spacecraft: Membrane and Inflatable Structures Technology for Space Applications, Edited by C.H.M. Jenkins, Progress in Astronautics and Aeronautics, Vol. 191, American Institute of Aeronautics and Astronautics, Reston, VA, 2001.

${ }^{5}$ West, J. L. and Derbès, B., "Solar Sail Vehicle System Design for the Geostorm Warning Mission," $41^{s t}$ AIAA/ASME/ASCE/AHS/ASC Structures, Structural Dynamics \& Materials Conference, AIAA-2000-5326, 2000.

${ }^{6}$ West, J. L., "The Geostorm Warning Mission: Enhanced Opportunity Based on New Technology," 14th AAS/AIAA Space Flight Mechanics Conference, AAS 2004-102, 2004.

${ }^{7}$ Lichodziejewski, D., Derbès, B., West, J., Reinert, R., Belvin, K., and Pappa, R. "Bringing an Effective Solar Sail Design Toward TRL 6," 39th AIAA/ASME/SAE/ASEE Joint Propulsion Conference and Exhibit, Huntsville, AL, AIAA 2003-4659, 2003.

${ }^{8}$ Lichodziejewski, D., Derbès, B., Reinert, R., Bevin, K., Slade, K., and Mann, T., "Development and Ground Testing of a Compactly Stowed Scalable Inflatably Deployed Solar Sail," $45^{\text {th }}$ AIAA/ASME/ASCE/AHS/ASC Structures, Structural Dynamics \& Materials Conference, Palm Springs, CA, AIAA-2004-1507, 2004.
} 
${ }^{9}$ Greschik, G. and Mikulas, M.M., "Design Study of a Square Solar Sail Architecture," Center for Aerospace Structures, University of Colorado, Boulder, CO.

${ }^{10}$ Derbès, B., Lichodziejewski, D., and Veal, G., "A Yank and Yaw Control System for Solar Sails," $14^{\text {th }}$ AAS/AIAA Space Flight Mechanics Conference, Maui, HI, AAS 2004-284, February 8-12, 2004.

${ }^{11}$ Derbès, B., Lichodziejewski, D., Ellis, J., and Scheeres, D., "Sailcraft Coordinate Systems and Format for Reporting Propulsive Performance," AAS 14th AAS/AIAA Space Flight Mechanics Conference, Maui, HI, AIAA-2004-100, February 8-12, 2004.

${ }^{12}$ Lichodziejewski, D., Derbès, B., Slade, K., and Mann, T., "Vacuum Deployment and Testing of a four-quadrant Scalable Inflatable Rigidizable Solar Sail System," 46th AIAA/ASME/ASCE/AHS/ASC Structures, Structural Dynamics \& Materials Conference, Austin, TX, AIAA 2005-2122, 2005.

${ }^{13}$ Lichodziejewski, D., Derbès, B., Galena, D., and Friese, D., "Vacuum Deployment and Testing of a 4- Quadrant Scalable Inflatable Rigidizable Solar Sail System," 41st AIAA/ASME/SAE/ASEE Joint Propulsion Conference and Exhibit, Tucson, AZ, AIAA 2005-3927, 2005.

${ }^{14}$ Lichodziejewski, D., Derbès, B., Galena, D., and Friese, D., "Vaccum Deployment and Testing of a 20M Solar Sail System," 47th AIAA/ASME/ASCE/AHS/ASC Structures, Structural Dynamics \& Materials Conference, Newport, RI, AIAA 2006-1705, 2006.

${ }^{15}$ Mann, T., Vaughn, B., Lichodziejewski, D., Derbes, B., and Sleight, D. "Ground Testing a 20- Meter Inflation Deployed Solar Sail," 47th AIAA/ASME/ASCE/AHS/ASC Structures, Structural Dynamics \& Materials Conference, Newport, RI, AIAA 2006-1707, 2006.

${ }^{16}$ NEiNastran User's and Reference Manual, Version 8.3, Noran Engineering, Inc, 2004.

${ }^{17}$ ABAQUS/Standard User's Manual, Version 6.5-4, Hibbitt, Karlsson, and Sorensen, Inc., 2005.

${ }^{18}$ Sleight, D. W., Michii, Y., Lichodziejewski, D., Derbès, B., Mann, T. O., Slade, K. N., and Wang, J. T., "Finite Element Analysis and Test Correlation of a 10-Meter Inflation-Deployed Solar Sail," 46th AIAA/ASME/ASCE/AHS/ASC Structures, Structural Dynamics \& Materials Conference, Austin, TX, AIAA 2005-2121, 2005.

${ }^{19}$ Sleight, D. W., Michii, Y., Lichodziejewski, D., Derbès, B., and Mann, T. O., "Structural Analysis of an Inflation-Deployed Solar Sail With Experimental Validation," 41st AIAA/ASME/SAE/ASEE Joint Propulsion Conference and Exhibit, Tucson, AZ, AIAA 2005-3727, 2005.

${ }^{20}$ Greschik, G., and Belvin, W., "The Ultimate in Passive Gravity Compensation for Vibration Testing and Some More," 46th AIAA/ASME/ASCE/AHS/ASC Structures, Structural Dynamics \& Materials Conference, Austin, TX, AIAA 2005-1839, 2005. 